\title{
Endoscopic submucosal dissection of malignant non-pedunculated colorectal lesions
}

\section{다(1)(웅}

\author{
Authors \\ Carl-Fredrik Rönnow ${ }^{1}$, Jacob Elebro ${ }^{2}$, Ervin Toth ${ }^{3}$, Henrik Thorlacius ${ }^{1}$
}

Institutions

1 Department of Clinical Sciences, Malmö, Section of Surgery, Skåne University Hospital, Lund University, Malmö, Sweden

2 Department of Clinical Sciences, Malmö, Section of Pathology, Skåne University Hospital, Lund University, Malmö, Sweden

3 Department of Clinical Sciences, Malmö, Section of Gastroenterology, Skåne University Hospital, Lund University, Malmö, Sweden

submitted 5.12.2017

accepted after revision $\quad$ 12.3.2018

\author{
Bibliography \\ DOI https://doi.org/10.1055/a-0602-4065 | \\ Endoscopy International Open 2018; 06: E961-E968 \\ (c) Georg Thieme Verlag KG Stuttgart · New York \\ ISSN 2364-3722
}

Corresponding author

Henrik Thorlacius, MD, PhD, Department of Clinical Sciences, Malmö, Section of Surgery, Skåne University Hospital, Lund University, S-205 02 Malmö, Sweden

Fax: +46-40-336207

henrik.thorlacius@med.lu.se

\begin{abstract}
Background and study aims Endoscopic submucosal dissection (ESD) is an established method for en bloc resection of large non-pedunculated colorectal lesions in Asia but dissemination of ESD in Western countries is limited. The aim of this study was to evaluate the role of ESD in the management of malignant non-pedunculated colorectal lesions in a European center.

Patients and methods Among 255 patients undergoing colorectal ESD between 2014 and 2016, 29 cases were identified as submucosal invasive cancers and included in this study. The main outcomes were en bloc, R0 and curative resection as well as procedural time, complications and recurrence.

Results Median tumor size was $40 \mathrm{~mm}$ (range 20 - $70 \mathrm{~mm}$ ). Thirteen cancers were located in the colon and 16 were located in the rectum. Procedural time was 89 minutes (range 18-594 minutes). Complete resection was achieved in 28 cases, en bloc and $\mathrm{R} 0$ resection rates were $83 \%$ and $69 \%$, respectively. Curative resection rate was $38 \%$. One case had a perforation in the sigmoid colon requiring emergency surgery. No significant bleeding occurred. Six patients underwent additional surgery after ESD, one of whom had residual tumor. One recurrence was detected in 20 patients that were followed-up endoscopically, median follow-up time was 13 months (range 2-30 months).

Conclusion ESD seems to be a safe and effective method for treating non-pedunculated malignant colorectal lesions after careful patient selection and proper endoscopic training.
\end{abstract}

\section{Introduction}

Colorectal cancer (CRC) is the third most frequent cancer-related cause of death among men and women in the world [1]. Conventional endoscopic resection, such as snare polypectomy and endoscopic mucosal resection (EMR) of benign polyps, reduces CRC incidence and mortality [2,3]. However, the role of endoscopic resection in management of patients with early CRC (i. e. submucosal invasion) remains elusive. Previous studies have shown that conventional endoscopic resection might be adequate for removal of pedunculated polyps with submu- cosal cancer given that the lesions are resected en bloc (i.e. in one piece) [4-6]. However, large $(>2 \mathrm{~cm})$ sessile and flat lesions are difficult to remove en bloc with conventional endoscopic resection methods which is thus not recommended if malignancy is suspected or known [7].

Endoscopic submucosal dissection (ESD) was developed in Japan during the 1990 s to achieve en bloc resection of large neoplasms in the stomach but has in recent years also been extended into management of large $(>2 \mathrm{~cm})$ and technically challenging benign colorectal polyps [8,9]. Large series on the efficacy of ESD in removing benign lesions show high en bloc re- 
section rates resulting in low numbers of recurrences [8-10]. Notably, ESD has been proven to be an eligible alternative to surgery in treating early gastric cancer in Japan [11]. However, there is limited data in the literature on the potential role of ESD in treatment of patients with non-pedunculated colorectal lesions with submucosal invasion. Curative resection is defined as $\mathrm{RO}$ resection of low-risk lesions, i.e. invasion less than $1000 \mu \mathrm{m}$ into the submucosa, exclusion of lymphovascular invasion, poor differentiation and tumor budding [7]. One recent study from Japan reported that ESD achieved a curative resection rate of $34 \%$ in 94 patients with flat and sessile polyps with submucosal invasion in the colon and rectum [12]. In a German study of 43 patients with malignant rectal lesions, a curative resection rate of $30 \%$ was observed [13]. However, data on ESD and removal of non-pedunculated malignant lesions in both colon and rectum is lacking in western countries.

In this study, we present our results with performing ESD in patients with large sessile and flat malignant lesions with submucosal invasion in both the colon and rectum in a large European center.

\section{Patients and methods}

\section{Patients}

We retrospectively reviewed medical records from 255 consecutive patients that underwent colorectal ESD at the endoscopy unit at Skåne University Hospital in Malmö, Sweden from January 2014 to December 2016. Indications for ESD were flat and sessile lesions larger than $20 \mathrm{~mm}$ in diameter as well as recurrences. Lesions were excluded if macroscopic appearance indicated advanced cancer (invasion below the submucosa) and when biopsies showed cancer unless comorbidity prohibited surgical resection (three cases). Cases with biopsy-confirmed cancers and cases with macroscopically suspected submucosal invasion were pretherapeutically investigated with computed tomography (CT) of abdomen and thorax to rule out metastatic disease and magnetic resonance imaging (MRI) for staging of rectal lesions. In total, we identified and included 29 cases of histologically verified submucosal invasive CRC that underwent ESD in this study.

\section{Tumors}

Tumor location was classified as follows; cecum, ascending colon, transverse colon, descending colon, sigmoid colon and rectum. Macroscopic appearance of the colorectal neoplasms was categorized in accordance to the Paris classification of superficial lesions [14]. Topical administration of $0.4 \%$ indigo carmine and narrowband imaging (NBI) was used to outline the lesions and to detect signs of invasive cancer, in addition to thorough inspection with white light. The NBI International Colorectal Endoscopic (NICE) classification was used for assessing the risk of submucosal cancer [15].

\section{ESD Procedure}

All procedures were performed by one endoscopist (H.T.) proficient in colorectal ESD. All patients underwent colonic cleansing (polyethylene glycol) prior to ESD and were given sedatives, analgesic and glucagon or scopolamine butyl bromide to reduce bowel movements, as described previously [16]. ESD was conducted using conventional video endoscope (GIF-H180 J and (F-H180Al, Olympus, Hamburg, Germany) with a disposable distal attachment (D-201-11804 or D-201-15004, Olympus) mounted onto the tip of the endoscope. Carbon dioxide was used for insufflation. Electrical cutting and coagulation was powered by VIO 300D (ERBE Elektromedizin, Tübingen, Germany). ESD was performed in a standardized manner using a Flush-knife (Fujifilm Europe GmbH, Düsseldorf, Germany) connected to a water jet pump, as described in detail previously [16]. Hemostatic forceps (Coagrasper, FD-411UR, Olympus) was used to prevent and treat bleeding. En bloc resection was classified as complete removal of lesions in one piece. Piecemeal resection was defined as removal of a lesion in more than one piece. Macroscopic complete resection was defined as the entire visible lesion being completely removed. After removal, resected specimens were retrieved by use of grasping forceps (FG-47L-1; Olympus) or a retrieval device (Roth Net, US Endoscopy, Mentor Ohio, United States). Remaining ulcers were carefully examined, pulsating and protruding vessel stumps were coagulated with the hemostatic forceps using a soft coagulation mode and the margins of the ulcers were carefully inspected to ensure complete removal of the lesions. The specimens were pinned onto a hard plate to facilitate histological examination. Procedure time was defined as the time from incision with the Flush-knife to complete removal of the lesion. The main outcomes were en bloc, R0 and curative resection rate as well as procedural time, complications and recurrence.

\section{Histological evaluation}

Resected specimens were immersed in $10 \%$ formalin and sectioned serially at 3-mm intervals and all tissue was embedded for histological examination. Colorectal neoplasms were classified in accordance with the Vienna classification of gastrointestinal neoplasia $[17,18]$. The tumors were sub-classified based on depth of submucosal invasion, sm 1 ; <1000 $\mu \mathrm{m}$, sm2; $>1000 \mu \mathrm{m},<2000 \mu \mathrm{m}$ and $\mathrm{sm} 3 ;>2000 \mu \mathrm{m}$ [14]. R0 resection was defined as tumor-free vertical and lateral margins. R1 resection was defined as specimens with evidence of tumor cells on the vertical or lateral margins. RX was applied when the margins could not be reliably assessed, often including cases of extensive coagulation, piecemeal resection or fragmentation of the specimen after the procedure. Curative resection was defined according to ESGE guidelines as RO resection of low risk lesions, i.e. invasion less than $1000 \mu \mathrm{m}$ into the submucosa without lymphovascular invasion, poor differentiation and tumor budding [7].

\section{Complications and post-ESD management}

Immediate perforation was defined as defects with visible omentum or other tissue outside the muscle layer, such as transparent serosa, visualized during the procedure. Late perforation, detected after the procedure, was defined as free air in the abdomen on image studies or detected during emergency surgery. Immediate bleeding was defined as hemorrhage during the procedure causing abortion of the ESD. Late bleed- 


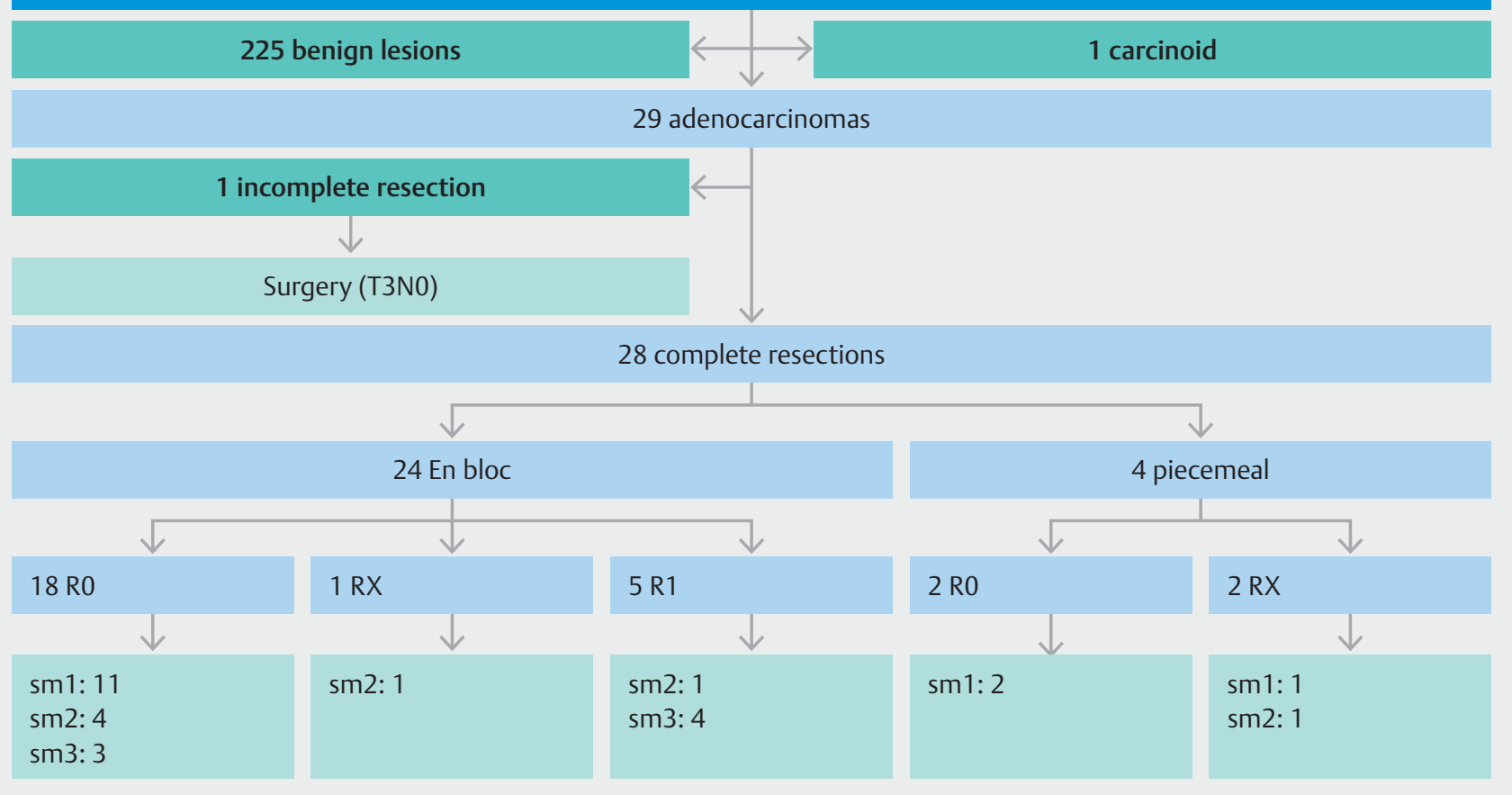

- Fig. 1 Flowchart of ESD procedure.

ing was defined as post-procedural clinical evidence of significant hemorrhage with melena or hematochezia within 14 days of the procedure. All patients' medical records were examined in search of complications up to 30 days after ESD. Complications were registered in accordance with the Clavien-Dindo classification of surgical complications (grade I-V) [19]. All patients were discussed at a post-procedural multidisciplinary team (MDT) conference. Recommendations varied from no follow-up in cases with aggravating comorbidity or high age to endoscopic surveillance and subsequent surgery. At endoscopic follow-up, biopsies were obtained for histological assessment of any suspicious tumor recurrence.

\section{Post-procedural care}

Most patients were managed as outpatients. The need for hospitalization after the procedure was evaluated on a case by case basis. Difficult location, long procedural time, perioperative perforation, major bleeding, advanced age and comorbidity were factors in favor of hospitalization.

\section{Statistics and Ethics}

Data are given as median and range. Informed consent was obtained after patients received a detailed explanation prior to the procedure, including risks of complications and the possibility of additional surgery due to complications or histological diagnosis of resected specimens.

This study was approved by the Regional Ethical Review Board, Lund University (Dnr:2017/1) and performed in accordance with the ethical principles of the Declaration of Helsinki.
Patient anonymity was guaranteed and all data were coded for this purpose.

\section{Results}

\section{Patient and tumor characteristics}

Two hundred fifty-five patients underwent colorectal ESD between January 2014 and December 2016 in our center. Two hundred twenty-five patients had benign histopathology and one patient had a carcinoid tumor and were excluded ( $\triangleright$ Fig. 1). Twenty-nine patients with confirmed adenocarcinoma were included in this study. Median age of these patients was 69 years (range $44-89$ years) and consisted of 13 females and 16 males. ASA score varied between I and IV ( $\triangleright$ Table 1). Twenty-seven patients had biopsies taken prior to ESD of which three showed adenocarcinoma (11\%). In spite of benign pathology in biopsies, 10 lesions appeared malignant to the endoscopist. These 10 patients, as well as the three patients with biopsy-confirmed adenocarcinoma, were further investigated with computed tomography (CT) and in selected cases, magnetic resonance imaging (MRI). None of the $13 \mathrm{CT}$ investigations detected any malignant process. MRI was performed in 10 patients with suspected rectal and distal sigmoid lesions, grading five cases as T0, one case as T1 and four cases as T2 tumors. All patients with confirmed and suspected CRC underwent MDT review and ESD was recommended in cases without biopsy-verified CRC and in patients not suitable for surgery due to advanced age or comorbidity. Median tumor size was $40 \mathrm{~mm}$, range 20 to $70 \mathrm{~mm}$. Thirteen cancers (45\%) were located in the 
- Table 1 Patient and tumor characteristics.

\begin{tabular}{|c|c|}
\hline Age (years) & 69 (range 44-89) \\
\hline Gender, male : female & $16: 13$ \\
\hline ASA score I: II: III : IV & $10: 12: 6: 1$ \\
\hline Tumor size (mm) & 40 (range $20-70$ ) \\
\hline \multicolumn{2}{|l|}{ Localization } \\
\hline - Rectum & $16(55 \%)$ \\
\hline - Sigmoid colon & $10(35 \%)$ \\
\hline - Transverse colon & $2(7 \%)$ \\
\hline Cecum & $1(3 \%)$ \\
\hline \multicolumn{2}{|c|}{ Type (Paris classification) } \\
\hline - Ila & $10(35 \%)$ \\
\hline - Is & $14(48 \%)$ \\
\hline - Ila +ls & $5(17 \%)$ \\
\hline \multicolumn{2}{|l|}{ LST type (Paris type Ila) } \\
\hline - Granular & 10 \\
\hline - Nongranular & 5 \\
\hline \multicolumn{2}{|l|}{ Risk of cancer ${ }^{1}$} \\
\hline - Ila & $9 \%$ \\
\hline - Is & $11 \%$ \\
\hline - Ila +ls & $31 \%$ \\
\hline \multicolumn{2}{|c|}{$\begin{array}{l}{ }^{1} \text { Percentage malignant lesions in each Paris classification group of all ESD } \\
\text { resected lesions }(\mathrm{N}=255)\end{array}$} \\
\hline
\end{tabular}

colon and 16 (55\%) were located in the rectum ( $\triangleright$ Table 1$)$. According to the Paris classification, $35 \%$ of the lesions were flat (Paris classification Ila), $48 \%$ were sessile (Paris classification Is) and $17 \%$ were combined flat and sessile (Paris classification $\mathrm{Ila}+\mathrm{Is})$. Of all 15 Paris-type Ila tumors 10 were LST-granular (LST-G) and five were LST-nongranular (LST-NG). According to Paris-type, the risk of cancer was $11 \%$ in Is, $9 \%$ in Ila, $31 \%$ in Ila + Is in all cases of ESD ( $\triangleright$ Table 1 ).

\section{ESD performance and oncologic outcome}

Complete tumor resection was achieved in 28 cases (97\%) of which 24 were en bloc and four were piecemeal resections ( $>$ Fig. 1). Thus, the en bloc ESD resection rate was $83 \%$ of all colorectal adenocarcinomas ( $>$ Table 2 ). One resection of a lesion in the sigmoid colon was incomplete due to perforation. Median time to complete the procedures was 89 minutes (range 18-594 minutes). R0 resection was achieved in 20 lesions amounting to an $\mathrm{R} 0$ resection rate of $69 \%$. RX resection rate was $10 \%$ and $\mathrm{R} 1$ resection rate was $17 \%$ ( $\triangleright$ Table 2$)$. The lateral margins were tumor-free in 26 cases (90\%) and could not be determined in two cases (7\%) due to piecemeal resection ( $\triangleright$ Table 3). Deep margins were tumor-negative in 21 cases (72\%) and uncertain in two cases (7\%) ( Table 3$)$. Notably, in five cases (17\%) tumor growth was identified at the deep mar-

\begin{tabular}{l|c|}
\hline \begin{tabular}{l} 
Table 2 Clinical outcome of ESD. \\
\hline CRCs treated with ESD
\end{tabular} & 29 \\
\hline Resection & $24(83 \%)$ \\
\hline - En bloc & $4(14 \%)$ \\
\hline - Piecemeal & $1(3 \%)$ \\
\hline - Incomplete & \\
\hline Margins & $20(69 \%)$ \\
\hline - R0 resection & $3(10 \%)$ \\
\hline - RX resection & $5(17 \%)$ \\
\hline - R1 resection & \\
\hline Complications & $4(14 \%)$ \\
\hline - Immediate perforation & 0 \\
\hline - Immediate bleeding & 0 \\
\hline - Late perforation & $1(3 \%)$ \\
\hline - Late bleeding & \\
\hline
\end{tabular}

gin ( $\triangleright$ Table 3). Depth of invasion was divided as follows: sm1: 14 cases ( $48 \%$ ), sm 2: seven cases (24\%) sm3: seven cases (24\%) ( $\triangleright$ Table 3). Lymphovascular involvement was observed in six cases $(21 \%)$ ( $\triangleright$ Table 3 ). None of the cancers were poorly differentiated. An example of a large rectal lesion with matching histology is demonstrated in $>$ Fig. $\mathbf{2 a}$, Fig. $\mathbf{2 b}$, and $>\mathbf{F i g . 2 c}$. Curative resection was observed in 11 of 29 cases (38\%) ( $\triangleright$ Table 3 ). Non-curative resection was observed in 14 cases due to deep submucosal infiltration (>sm1) and in two cases due to lymphovascular involvement. Two additional non-curative cases were due to one RX and one incomplete resection ( $\triangleright$ Table 3). Notably, 11 of the 12 potentially endoscopically curable cancers (92\%) were excised in a curative manner. Interestingly, $\mathrm{R} 0$ resection rate was $93 \%$ in all sm 1 adenocarcinomas (13/14).

\section{Complications}

In total four suspected immediate perforations occurred of which three were located in the rectum and managed conservatively (Clavien-Dindo II) ( $\triangleright$ Table 2 ). The fourth perforation occurred in the sigmoid colon and was not manageable with clips, requiring emergency surgery (Clavien-Dindo IIIb). The postoperative course was uneventful and pathological assessment of the resected sigmoid segment revealed a T3N0 tumor. No significant bleeding occurred during the procedures. One patient was admitted 12 days after the procedure due to blood in the stool, which was managed conservatively (Clavien-Dindo II) ( Table 2).

\section{Post-ESD management and follow-up}

Nineteen patients (66\%) were managed as outpatients. All patients were reviewed at a post-ESD MDT conference, which resulted in eight patients being recommended surgery. All lesions in these patients exhibited deep submucosal invasion ( $\geq s \mathrm{~s} 2)$ in the ESD specimen ( $\triangleright$ Table 3 ). Two patients refused surgery 
- Table 3 ESD performance, histopathology and management.

\begin{tabular}{|c|c|c|c|c|c|c|c|c|}
\hline Biopsy & $\begin{array}{l}\text { Pre-ESD } \\
\text { diagnosis }\end{array}$ & Resection & $\begin{array}{l}\text { Lateral } \\
\text { margin }\end{array}$ & $\begin{array}{l}\text { Deep } \\
\text { Margin }\end{array}$ & $\begin{array}{l}\text { Invasion } \\
\text { depth }\end{array}$ & $\begin{array}{l}\text { Lympho- } \\
\text { vascular } \\
\text { invasion }\end{array}$ & $\begin{array}{l}\text { Further manage- } \\
\text { ment (months) }\end{array}$ & Result \\
\hline LGD & Adenoma & En-bloc & Ro & $\mathrm{R} 1$ & SM3 & Yes & Surgery & $\begin{array}{l}\text { No residual cancer in } \\
\text { resected specimen }\end{array}$ \\
\hline LGD & Adenoma & Aborted $^{1}$ & - & - & - & No & Emergency resection & $\begin{array}{l}\text { T3N0 tumor in resected } \\
\text { specimen }\end{array}$ \\
\hline HGD & Adenoma & En-bloc ${ }^{1}$ & Ro & Ro & $\mathrm{Sm} 1$ & Yes & Endoscopy (18) & No recurrence or residue \\
\hline LGD & Adenoma & En-bloc & Ro & Ro & $\mathrm{Sm} 1$ & No & Endoscopy (28) & No recurrence or residue \\
\hline LGD & Adenoma & En-bloc & Ro & Ro & Sm1 & No & Endoscopy (6) & No recurrence or residue \\
\hline HGD & Adenoma & En-bloc & Ro & Ro & $\mathrm{Sm} 2$ & Yes & Endoscopy (19) & No recurrence or residue \\
\hline LGD & Adenoma & En-bloc & Ro & Ro & $\mathrm{Sm} 1$ & No & No follow-up 2 & - \\
\hline LGD & Adenoma & Piecemeal ${ }^{1}$ & Ro & Ro & $\mathrm{Sm} 1$ & No & Endoscopy (10) & No recurrence or residue \\
\hline LGD & Adenoma & En-bloc & Ro & Ro & Sm1 & Yes & Endoscopy (12) & No recurrence or residue \\
\hline LGD & Adenoma & En-bloc & Ro & R1 & $\mathrm{Sm} 3$ & No & Surgery & $\begin{array}{l}\text { No residual cancer in } \\
\text { resected specimen }\end{array}$ \\
\hline LGD & Adenoma & En-bloc & Ro & Ro & $\mathrm{Sm} 3$ & No & Surgery & $\begin{array}{l}\text { No residual cancer in } \\
\text { resected specimen }\end{array}$ \\
\hline LGD & Adenoma & En-bloc & Ro & Ro & $\mathrm{Sm} 3$ & No & Endoscopy $(6)^{3}$ & No recurrence or residue \\
\hline HGD & Adenoma & En-bloc & Ro & Ro & $\mathrm{Sm} 3$ & No & Surgery & No recurrence or residue \\
\hline- & Adenoma & En-bloc & Ro & Ro & $\mathrm{Sm} 1$ & No & Awaits endoscopy & No recurrence or residue \\
\hline- & Adenoma & En-bloc & Ro & R0 & Sm1 & No & Endoscopy (4) & No recurrence or residue \\
\hline LGD & Adenoma & En-bloc & Ro & Ro & $\mathrm{Sm} 2$ & No & MRI + endoscopy (3) & No recurrence or residue \\
\hline LGD & Suspected Ca & Piecemeal & Ro & R0 & $\mathrm{Sm} 1$ & No & No follow-up 2 & - \\
\hline LGD & Suspected Ca & Piecemeal & $\mathrm{RX}$ & Ro & $\mathrm{Sm} 1$ & No & Endoscopy (20) & No recurrence or residue \\
\hline LGD & Suspected Ca & Piecemeal & $\mathrm{RX}$ & $\mathrm{RX}$ & $\mathrm{Sm} 2$ & Yes & MRI + Endoscopy (24) & No recurrence or residue \\
\hline HGD & Suspected Ca & En-bloc & Ro & Ro & $\mathrm{Sm} 1$ & No & Endoscopy (21) & No recurrence or residue \\
\hline LGD & Suspected Ca & En-bloc & Ro & Ro & $\mathrm{Sm} 2$ & No & Surgery & $\begin{array}{l}\text { No residual cancer in } \\
\text { resected specimen }\end{array}$ \\
\hline $\mathrm{Ca}$ & Confirmed $\mathrm{Ca}$ & En-bloc ${ }^{1}$ & Ro & $\mathrm{RX}$ & Sm2 & No & Surgery & $\begin{array}{l}\text { Residual cancer in } \\
\text { resected specimen }\end{array}$ \\
\hline HGD & Suspected Ca & En-bloc & Ro & Ro & Sm1 & No & Endoscopy (15) & $\begin{array}{l}\text { Recurrence, Radiation } \\
\text { therapy or surgery }\end{array}$ \\
\hline $\mathrm{Ca}$ & Confirmed Ca & En-bloc & Ro & R1 & $\mathrm{Sm} 3$ & No & Endoscopy (2) & No recurrence or residue \\
\hline HGD & Suspected Ca & En-bloc & Ro & Ro & $\mathrm{Sm} 2$ & Yes & MRI + Endoscopy $(7)^{3}$ & No recurrence or residue \\
\hline HGD & Suspected Ca & En-bloc & Ro & Ro & Sm1 & No & Endoscopy (8) & No recurrence or residue \\
\hline HGD & Suspected Ca & En-bloc & Ro & RO & Sm1 & No & Endoscopy (6) & No recurrence or residue \\
\hline $\mathrm{Ca}$ & Confirmed Ca & En-bloc & Ro & R1 & $\mathrm{Sm} 3$ & No & Endoscopy (3) & No recurrence or residue \\
\hline LGD & Suspected Ca & En-bloc & Ro & R1 & $\mathrm{Sm} 2$ & No & Endoscopy (14) & No recurrence or residue \\
\hline \multicolumn{9}{|c|}{$\begin{array}{l}\text { LGD, low-grade dysplasia; HGD, high-grade dysplasia; Ca, cancer; MRI, magnetic resonance imaging; MDT, multidisciplinary team } \\
{ }^{1} \text { Perforation during ESD } \\
{ }^{2} \text { Due to spread of non-colorectal cancer } \\
{ }^{3} \text { Patient refused surgery despite MDT recommendation. }\end{array}$} \\
\hline
\end{tabular}



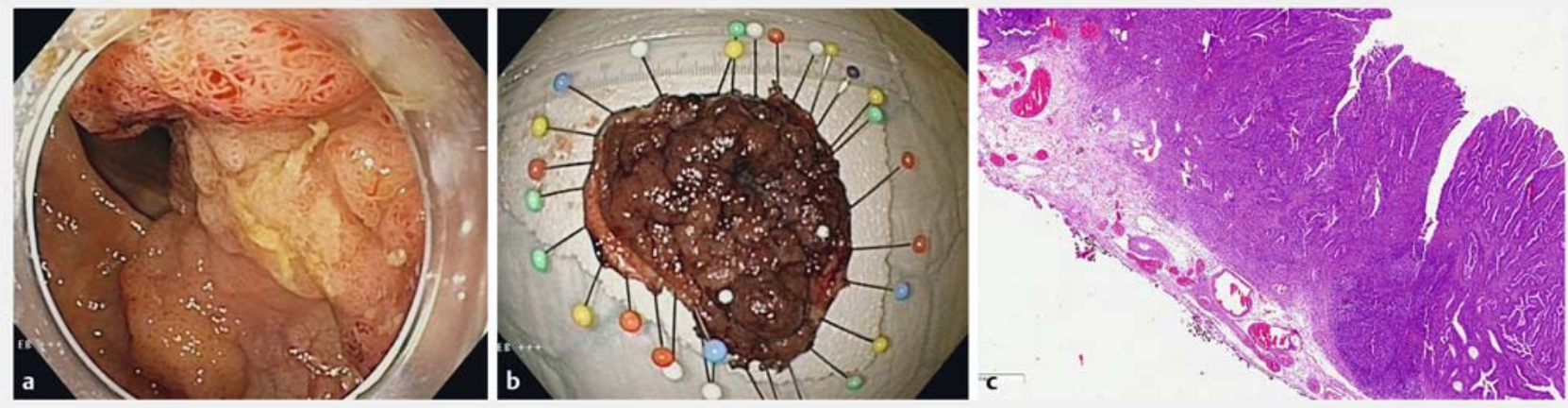

- Fig. $2 a-c$ A large $(70 \times 70 \mathrm{~mm})$, sessile (Paris classification Is) rectal lesion as seen with normal endoscopic view and after en bloc resection. Corresponding histology showed submucosal growth <2000 $\mu \mathrm{m}(\mathrm{sm} 2)$, both vertical and lateral margins free from growth and no sign of lymphovascular involvement.

and were followed endoscopically without any recurrences being detected, 12 respectively 14 months after ESD. Of those operated, one out of six patients had residual tumor but none had any positive lymph nodes in the resected specimen. In nine cases of non-curative resections, surgery was considered but due to advanced age or comorbidity in combination with the patient's reluctance to undergo surgery, a conservative approach was adopted with intensified radiological and endoscopic follow-up ( $\triangleright$ Table 3 ). In all, ESD circumvented surgery as first-line treatment in $76 \%$ of patients of adenocarcinomas (22/29). In total, 20 patients were followed up endoscopically, with a median follow-up time of 13 months (range 2-30 months) ( $\bullet$ Table 3 ). One recurrence $(3 \%)$ was detected 15 months after curative ESD resection in the rectum. Notably this patient had a normal control colonoscopy 6 months after ESD. Furthermore, no post-ESD stenosis was detected during control endoscopy.

Two patients were diagnosed with metastasized non-colorectal cancer (breast and adrenal cancer) shortly after ESD was performed and were not followed up regarding their CRC since they were in a palliative state.

\section{Discussion}

Colorectal adenocarcinoma is one of the most frequent malignancies in the world and poses a major challenge to the health care system. Convincing data suggest that early cancer limited to the submucosa of the bowel wall (T1 cancer) with low risk of concomitant lymph node metastasis can be treated by endoscopic resection as long as these tumors are removed en bloc [4-6]. The problem is that most malignant non-pedunculated colorectal lesions are larger than $2 \mathrm{~cm}$ which makes en bloc resection with conventional endoscopic methods difficult [20]. Instead, ESD allows en bloc resection of larger colorectal polyps irrespective of size. In the current study, we showed that ESD can be a safe and effective method to treat patients with malignant non-pedunculated lesions in the colon and rectum in western countries.
One significant challenge when managing large and advanced colorectal lesions is pretherapeutic evaluation of risk of malignancy and depth of submucosal invasion [21]. Biopsies are notoriously unreliable and often underestimate risk of malignancy in colorectal polyps [22,23]. Herein, biopsies taken prior to resection exhibited cancer in only 3 out of 27 patients, corresponding to $11 \%$, which is in line with a recent German study of ESD on rectal lesions [13]. Accordingly, macroscopic evaluation, including size, shape (type), vascular and crypt patterns should be used to determine potential risk of cancer and depth of invasion. Herein, 10 cases were suspected to be malignant based on morphological criteria. Thus, the remaining 16 cases of cancers were diagnosed only after resection and microscopic evaluation, indicating that macroscopic evaluation is difficult and that more than half of non-pedunculated malignant colorectal polyps are surprise findings. One incomplete resection was due to perforation of a T3NO tumor in the sigmoid colon. This case illustrates that pretherapeutic evaluation can be difficult since biopsies had shown tubular adenoma with low-grade dysplasia and the macroscopic appearance was not consistent with advanced cancer.

In the current study, MRI was used pretherapeutically in 10 malignant lesions of which MRI could not detect any lesion in five cases and in four cases MRI erroneously reported T2 cancers. MRI correctly diagnosed T1 cancer in 1 out 10 cases. Thus, reliability and accuracy of MRI in managing non-pedunculated T1 lesions seems to be poor and of little use, which is supported by one previous study on early CRC [24]. On top of that, conventional imaging methods such as MRI, CT and endoscopic ultrasound cannot effectively discriminate the detailed level of submucosal tumor cell infiltration (sm1-3), which is pivotal for treatment decisions $[25,26]$. Taken together, pretherapeutic diagnosis remains a challenge and development of refined methods to evaluate depth of invasion in the submucosa is critical for improving clinical management of early CRC.

In our material on 255 colorectal lesions larger than $2 \mathrm{~cm}$, incidence of cancer was found to be $12 \%$, which is similar to other studies reporting a cancer rate of $13 \%$ to $23 \%$, suggesting that malignant lesions are common in this group of advanced polyps 
in the colon and rectum $[9,12,13,17]$. En bloc resection is urgently recommended if lesions are suspected of being malignant. In fact, piecemeal resection of malignant lesions is an independent risk factor for incomplete resection and cancer recurrence [4,12]. Two studies from Japan have shown that ESD is associated with a low recurrence rate after removal of malignant non-pedunculated lesions in the colon (0\%) and rectum (6\%) with low-risk criteria $[5,12]$. ESD is a technically difficult procedure and despite an increase in reports from the West, dissemination of ESD outside Asia has been slow [28-32]. At present the role of ESD in western countries is under investigation and the specific role of ESD for treatment of malignant non-pedunculated colorectal lesions is unknown. In our material on colorectal ESD in a European center, we found that the en bloc resection rate was $83 \%$ and $\mathrm{R} 0$ resection was $69 \%$. Our results align with a recent study on submucosal cancers in the rectum reporting en bloc resection and $\mathrm{R} 0$ resection rates of $81 \%$ and $65 \%$, respectively [13]. Moreover, a recent study from Japan found an $\mathrm{R} 0$ resection rate of $69 \%$ in 94 patients with colorectal cancers undergoing ESD [12]. It is obvious that the en bloc resection and $\mathrm{R} 0$ resection rate is lower in general in malignant compared to benign colorectal lesions. More importantly, we found herein a curative resection rate of $38 \%$ of malignant non-pedunculated lesions in the colon and rectum. Comparable studies on ESD and early CRC in Japan have reported curative resection rates ranging from $16 \%$ to $50 \%[9,12$, $33-35$ ]. Thus, it is possible to achieve similar results in terms of curative ESD treatment of early CRC in western countries as in Japan. The reason for non-curative resection was submucosal invasion more than $1000 \mu \mathrm{m}$ in 15 out of 18 non-curative cases, which is in line with observations from Germany and Japan [12, 13]. The value of ESD is illustrated by the finding herein that ESD resulted in $92 \%$ curative resections of all cancer cases being potentially endoscopically curable, according to international guidelines [7]. In this context, it is important to note, knowing the unreliable outcome of normal biopsies and conventional imaging, that a non-curative ESD also serves as an optimized staging procedure ("complete biopsy") facilitating further treatment decisions [33]. Although pretherapeutic diagnosis is difficult, we recommend that ESD is used in unclear cases in order to obtain a more accurate histopathological diagnosis in order to avoid cases of unnecessary surgery. In fact, there is no disadvantage for patients with high risk lesions to undergo surgery after ESD, i. e. after a "complete biopsy" [36].

Further management of patients was highly individual and patient attitude was taken in consideration. Of the 18 patients who had non-curative resections, eight were recommended for surgery at the MDT conference. Of these eight cases, three had sm2 and five had sm3 lesions. Two patients refused surgery and underwent close surveillance. Six patients finally underwent surgical resection, one of whom had residual cancer and no case with positive lymph nodes was detected. It should be noted that the relatively short follow-up time of 13 months limits conclusions about long-term outcome. Notably, one recurrence in 20 patients was surprisingly detected 15 months after a curative R0 ESD resection. This observation raises the question whether ESD wounds should be washed in analogy to rectal washout during anterior resections of rectal cancers to deplete free-floating cells and further reduce risk of recurrence.

One limitation of this investigation is the retrospective nature lacking randomization against a control group. However, it is questionable whether it would be ethically acceptable to compare ESD with EMR since that would have resulted in several piecemeal resections known to be associated with higher rates of incomplete resection and cancer recurrence $[4,12]$. Another limitation is that all ESD procedures were conducted by only one endoscopist with a high level of expertise and whether findings in the current study can be widely extrapolated to other western centers is uncertain and remains to be studied. At the moment, we recommend that ESD for potentially malignant non-pedunculated colorectal lesions only be offered by experts in invasive endoscopy at specialized centers in western countries.

\section{Conclusion}

Taken together, our results indicate that ESD can be safe and effective for resecting malignant non-pedunculated colorectal lesions in a European center. We conclude that ESD could be a feasible option for patients with suspected and known superficial malignancies in the colon and rectum.

\section{Competing interests}

None

\section{References}

[1] American Cancer Society. Cancer Facts and Figures 2012.

[2] Winawer S], Zauber AG, Ho MN et al. Prevention of colorectal cancer by colonoscopic polypectomy. The National Polyp Study Workgroup. N Engl J Med 1993; 329: $1977-1981$

[3] Zauber AG, Winawer S], O'Brien M] et al. Colonoscopic polypectomy and long-term prevention of colorectal-cancer deaths. N Engl J Med 2012; 366: 687-696

[4] Backes Y, de Vos Tot Nederveen Cappel WH, van Bergeijk J et al. Risk for incomplete resection after macroscopic radical endoscopic resection of t1 colorectal cancer: a multicenter cohort study. Am J Gastroenterol 2017; 112: $785-796$

[5] Yoda Y, Ikematsu H, Matsuda T et al. A large-scale multicenter study of long-term outcomes after endoscopic resection for submucosal invasive colorectal cancer. Endoscopy 2013; 45: 718-724

[6] Bartel M], Brahmbhatt BS, Wallace MB. Management of colorectal T1 carcinoma treated by endoscopic resection from the Western perspective. Dig Endosc 2016; 28: 330 - 341

[7] Pimentel-Nunes P, Dinis-Ribeiro M, Ponchon T et al. Endoscopic submucosal dissection: European Society of Gastrointestinal Endoscopy (ESGE) Guideline. Endoscopy 2015; 47: 829-854

[8] Repici A, Hassan C, De Paula Pessoa D et al. Efficacy and safety of endoscopic submucosal dissection for colorectal neoplasia: a systematic review. Endoscopy 2012; 44: 137-150

[9] Saito Y, Uraoka T, Yamaguchi Y et al. A prospective, multicenter study of 1111 colorectal endoscopic submucosal dissections (with video). Gastrointest Endosc 2010; 72: 1217 - 1225 
[10] Lee EJ, Lee JB, Lee SH et al. Endoscopic submucosal dissection for colorectal tumors $-1,000$ colorectal ESD cases: one specialized institute's experiences. Surg Endosc 2013; 27: 31 - 39

[11] Ono H, Kondo H, Gotoda T et al. Endoscopic mucosal resection for treatment of early gastric cancer. Gut 2001; 48: 225 -229

[12] Yamada M, Saito Y, Takamaru H et al. Long-term clinical outcomes of endoscopic submucosal dissection for colorectal neoplasms in 423 cases: a retrospective study. Endoscopy 2017; 49: $233-242$

[13] Probst A, Ebigbo A, Markl B et al. Endoscopic submucosal dissection for early rectal neoplasia: experience from a European center. Endoscopy 2017; 49: $222-232$

[14] [Anonymous] The Paris endoscopic classification of superficial neoplastic lesions: esophagus, stomach, and colon: November 30 to December 1, 2002. Gastrointest Endosc 2003; 58: S3-43

[15] Hayashi N, Tanaka S, Hewett DG et al. Endoscopic prediction of deep submucosal invasive carcinoma: validation of the narrow-band imaging international colorectal endoscopic (NICE) classification. Gastrointest Endosc 2013; 78: 625-632

[16] Thorlacius H, Uedo N, Toth E. Implementation of endoscopic submucosal dissection for early colorectal neoplasms in Sweden. Gastroenterol Res Pract 2013; 2013: 758202

[17] Schlemper RJ, Riddell RH, Kato $Y$ et al. The Vienna classification of gastrointestinal epithelial neoplasia. Gut 2000; 47: 251-255

[18] Dixon MF. Gastrointestinal epithelial neoplasia: Vienna revisited. Gut 2002; 51: $130-131$

[19] Dindo D, Demartines N, Clavien PA. Classification of surgical complications: a new proposal with evaluation in a cohort of 6336 patients and results of a survey. Ann Surg 2004; 240: 205-213

[20] Saito Y, Fujii T, Kondo $\mathrm{H}$ et al. Endoscopic treatment for laterally spreading tumors in the colon. Endoscopy 2001; 33: 682-686

[21] Kaminski MF, Hassan C, Bisschops R et al. Advanced imaging for detection and differentiation of colorectal neoplasia: European Society of Gastrointestinal Endoscopy (ESGE) Guideline. Endoscopy 2014; 46: $435-449$

[22] Gondal G, Grotmol T, Hofstad B et al. Biopsy of colorectal polyps is not adequate for grading of neoplasia. Endoscopy 2005; 37: 1193-1197

[23] Absar MS, Haboubi NY. Colonic neoplastic polyps: biopsy is not efficient to exclude malignancy. The Trafford experience. Tech Coloproctol 2004; 8: (Suppl. 02): s257-260

[24] Bipat S, Glas AS, Slors FJ et al. Rectal cancer: local staging and assessment of lymph node involvement with endoluminal US, CT, and MR imaging - a meta-analysis. Radiology 2004; 232: 773 - 783
[25] Lutz MP, Zalcberg JR, Glynne-Jones R et al. Second St. Gallen European Organisation for Research and Treatment of Cancer Gastrointestinal Cancer Conference: consensus recommendations on controversial issues in the primary treatment of rectal cancer. Eur J Cancer 2016; 63: $11-24$

[26] Yamada T, Shimura T, Ebi M et al. Subset analysis of a multicenter, randomized controlled trial to compare magnifying chromoendoscopy with endoscopic ultrasonography for stage diagnosis of early stage colorectal cancer. PLoS One 2015; 10: e0134942

[27] Sauer M, Hildenbrand R, Oyama T et al. Endoscopic submucosal dissection for flat or sessile colorectal neoplasia $>20 \mathrm{~mm}$ : A European single-center series of 182 cases. Endosc Int Open 2016; 4: E895 E900

[28] Saunders BP, Tsiamoulos ZP. Endoscopic mucosal resection and endoscopic submucosal dissection of large colonic polyps. Nat Rev Gastroenterol Hepatol 2016; 13: 486-4966

[29] Neuhaus H. ESD around the world: Europe. Gastrointest Endosc Clin N Am 2014; 24: 295-311

[30] Fuccio L, Hassan C, Ponchon T et al. Clinical outcomes after endoscopic submucosal dissection for colorectal neoplasia: a systematic review and meta-analysis. Gastrointest Endosc 2017; 86: 74- 86 e17

[31] Burgess NG, Bourke M]. Endoscopic resection of colorectal lesions: The narrowing divide between East and West. Dig Endosc 2016; 28: 296-305

[32] Bialek A, Pertkiewicz ], Karpinska K et al. Treatment of large colorectal neoplasms by endoscopic submucosal dissection: a European singlecenter study. Eur J Gastroenterol Hepatol 2014; 26: 607-615

[33] Asayama N, Oka S, Tanaka S et al. Endoscopic submucosal dissection as total excisional biopsy for clinical T1 colorectal carcinoma. Digestion 2015; 91: 64-69

[34] Tanaka S, Oka S, Kaneko I et al. Endoscopic submucosal dissection for colorectal neoplasia: possibility of standardization. Gastrointest Endosc 2007; 66: $100-107$

[35] Tamaru Y, Oka S, Tanaka S et al. Long-term outcomes after treatment for T1 colorectal carcinoma: a multicenter retrospective cohort study of Hiroshima GI Endoscopy Research Group. J Gastroenterol 2017; 52: $1169-1179$

[36] Rickert A, Aliyev R, Belle S et al. Oncologic colorectal resection after endoscopic treatment of malignant polyps: does endoscopy have an adverse effect on oncologic and surgical outcomes? Gastrointest Endosc 2014; 79: 951 - 960 